\title{
Efeitos da Dessecação de Plantas de FeiJão sobre a gualidade de Sementes ARmazenadas ${ }^{1}$
}

\author{
Effects of Bean Plant Desiccation on Quality of Stored Seeds
}

\author{
SANTOS, J.B. ${ }^{2}$, FERREIRA, E.A. ${ }^{3}$, FERREIRA, E.M. ${ }^{4}$, SILVA, A.A. ${ }^{5}$ e FERREIRA, L.R. ${ }^{5}$
}

RESUMO - Objetivou-se neste trabalho avaliar o efeito da dessecação química de plantas de feijão, em pré-colheita, sobre a qualidade de sementes armazenadas. A dessecação na cultura foi realizada utilizando-se quatro doses de carfentrazone-ethyl (0, 10, 30 e $\left.60 \mathrm{~g} \mathrm{ha}^{-1}\right)$, aplicadas aos 30 dias após o florescimento, no final do estádio $\mathrm{R}_{8}$, quando as sementes já haviam atingido a maturidade fisiológica. As sementes, depois de colhidas e beneficiadas, foram acondicionadas em câmara fria $\left(12^{\circ} \mathrm{C}\right.$ e $70 \%$ de umidade relativa) por 80 dias. Após esse período, as sementes foram separadas em dois tamanhos: maiores (retidas em peneira de crivo oblongo 16/64" x 19,05 mm) e menores (as que passaram pela mesma peneira). Além do teste de germinação (TG) e do índice de velocidade de emergência (IVE), avaliou-se também a sanidade das sementes por meio do blotter test. Sementes oriundas de plantas dessecadas com carfentrazone-ethyl, na dose de $60 \mathrm{~g} \mathrm{ha}^{1}$, apresentaram índice de plântulas normais abaixo de $10 \%$. As sementes maiores foram mais sensiveis ao produto, observandose, mesmo na dose de $10 \mathrm{~g} \mathrm{ha}^{-1}, 44 \%$ de plântulas anormais. Não se observou efeito dos tratamentos sobre a sanidade das sementes. Considerando que, anteriormente ao armazenamento, a germinação das sementes avaliadas e a emergência de suas plântulas não eram afetadas pelo carfentrazone-ethyl, conclui-se que esse produto prejudica a qualidade das sementes após o armazenamento por 80 dias.

Palavras-chave: carfentrazone-ethyl, índice de velocidade de emergência, teste de germinação, teste de sanidade, Phaseolus vulgaris.

\begin{abstract}
This study aimed to evaluate the effect of chemical desiccation on quality of stored bean seeds at pre-harvest. Desiccation was achieved by applying four rates $\left(0,10,30\right.$ and $\left.60 \mathrm{~g} \mathrm{ha}^{-1}\right)$ of carfentrazone-ethyl, 30 days after flowering at the end of $R_{8}$ stage, when the seeds had reached physiological maturity. After harvest, the seeds were stored $\left(12^{\circ} \mathrm{C}\right.$ and $70 \%$ of relative humidity) during 80 days. The seeds were then classified "larger" (retained in 16/64" x 19.05mm sieves) and "small" (passed through 16/64" $x 19.05$ sieves). Seed sanity was evaluated by applying the "blotter test", as well as the germination test and emergence velocity index. Index of abnormal seedlings above 90\% was obtained in seeds from plants desiccated in $60 \mathrm{~g} \mathrm{ha}^{-1}$ of carfentrazoneethyl. The larger seeds were more sensitive to the product and no treatment effect on seed sanity was verified. Considering that prior to storage time, seed germination and seedling emergence were not affected by carfentrazone-ethyl, it was concluded that such product has a negative effect on the quality of the seeds after 80-day storage.
\end{abstract}

Keywords: carfentrazone-ethyl, emergence index, germination test, blotter test, Phaseolus vulgaris.

Recebido para publicação em 25/1/2005 e na forma revisada em 25/11/2005.

Bolsista Pós-Doutor do Departamento de Fitotecnia da UFV, 36570-000 Viçosa-MG, <jbarbosasantos@yahoo.com.br>; ${ }^{3}$ Doutorando do Departamento de Fitotecnia da UFV; ${ }^{4}$ Doutoranda do Departamento de Fitopatologia da UFV; ${ }^{5}$ Professor do Departamento de Fitotecnia da UFV. 


\section{INTRODUÇÃO}

A utilização de dessecantes para antecipação da colheita de sementes tem sido observada em diversas culturas, principalmente soja (Durigan \& Carvalho, 1980; Lacerda et al., 2001), milho (Magalhães et al., 2002) e feijão (Domingos et al., 1997, 2000). O emprego dessa tecnologia tem sido vantajoso, devido à redução da umidade, à uniformidade da maturação e à obtenção de sementes com qualidade superior (Lacerda et al., 2001, 2003).

Na cultura do feijão, o emprego de dessecantes é assunto relativamente novo; todavia, o interesse por essa prática vem aumentando gradativamente em algumas regiões produtoras, com o objetivo de reduzir os inconvenientes causados à colheita por infestações tardias de plantas daninhas, ou mesmo liberar a área mais rápido para a sucessão cultural.

O momento ideal para se fazer a colheita de sementes do feijão é logo após a maturidade fisiológica, quando o vigor, a germinação e a matéria seca são elevados. No entanto, quando colhida nessa ocasião, a planta ainda se encontra com elevado número de folhas e ramos verdes e úmidos, que dificultam o uso do maquinário, além de ocorrer maior injúria mecânica, devido ao elevado teor de água nas sementes (Portela \& Cobucci, 1999). Alguns aspectos a serem considerados quando se pretende usar dessecantes químicos são os reflexos do produto na qualidade da semente (redução no vigor de plântulas, menor rendimento de grãos, eventual ocorrência de resíduos tóxicos no produto colhido) e a época de aplicação de tais produtos.

Diversos resultados positivos na qualidade das sementes têm sido obtidos em avaliações realizadas logo após a colheita. Contudo, poucos são os trabalhos que avaliaram esse efeito após determinado período de armazenamento das sementes colhidas (Domingos et al., 2000). Entretanto, o conhecimento dos efeitos de dessecantes no período de armazenamento é de grande importância, pois a armazenagem das sementes após a colheita se faz necessária, uma vez que possibilita a semeadura nas épocas mais propícias à obtenção de resultados econômicos e à conservação e intercâmbio de germoplasma (Guimarães et al., 2004).
Uma das novas moléculas que estão sendo desenvolvidas para dessecação em plantio direto e/ou em aplicações dirigidas é o carfentrazone-ethyl. Em diversos estudos (Corrêa \& Borges, 2000; Osipe et al., 2000), esse herbicida tem-se mostrado muito eficiente no controle de diversas espécies de plantas daninhas que apresentam certa tolerância ao glyphosate, como a trapoeraba (Commelina spp.). O carfentrazone-ethyl também já foi avaliado como dessecante nas culturas da canola (Marchiori Jr. et al., 2002) e da soja (Inoue et al., 2003). Esse produto pertence ao grupo químico das aril-triazolinonas e tem como mecanismo de ação a inibição da protoporfirinogênio oxidase (PPO ou PROTOX), que é a enzima envolvida na rota biossintética da clorofila (HRAC, 2001). Logo, nas plantas sensíveis tratadas com esse herbicida ocorre acúmulo de protoporfirinogênio IX, que, na presença da luz, está envolvido na formação de oxigênio singleto, responsável pela peroxidação das membranas. Com isso, tem-se rápida dessecação das plantas tratadas, sendo os sintomas observados no mesmo dia da aplicação (Corrêa \& Borges, 2000).

Marchiori Jr. et al. (2002), utilizando o carfentrazone-ethyl (30 $\left.\mathrm{g} \mathrm{ha}^{-1}\right)$ como dessecante para produção de sementes de canola, verificaram que esse produto permitiu a antecipação de sete dias na colheita, sem interferir na produtividade e na qualidade fisiológica das sementes; contudo, não avaliaram o efeito do tempo de armazenamento sobre a garantia de qualidade nas sementes.

Conforme avaliado em trabalho anterior (Santos et al., 2005), a dessecação com carfentrazone-ethyl realizada nas mesmas condições propostas para este trabalho, imediatamente após a colheita e o beneficiamento das sementes de feijão, não interferiu na germinação das mesmas e nem na emergência das plântulas do cultivar Talismã. Dessa forma, o objetivo deste trabalho foi avaliar o efeito da aplicação do carfentrazone-ethyl para dessecação de plantas de feijão sobre a qualidade das sementes após determinado período de armazenamento.

\section{MATERIAL E MÉTODOS}

O cultivo do feijoeiro (cultivar Talismã) foi em campo experimental pertencente ao 
Departamento de Fitotecnia da Universidade Federal de Viçosa, em solo classificado como Argissolo Vermelho-Amarelo, fase terraço, durante o período de janeiro a abril de 2004 , com densidade populacional de 28 30 plantas $\mathrm{m}^{-2}$.

O carfentrazone-ethyl foi aplicado 30 dias após o florescimento do feijoeiro no ponto de maturidade fisiológica das sementes, ao final do estádio $\mathrm{R}_{8}$, quando se inicia a mudança de cor destas (Cruz et al., 1993). A dessecação foi realizada utilizando-se um pulverizador costal pressurizado com gás carbônico $\left(\mathrm{CO}_{2}\right)$, aplicando o equivalente a $200 \mathrm{~L} \mathrm{ha}^{-1}$ de calda. Os tratamentos, em número de oito, foram constituídos pela combinação de quatro doses do dessecante $\left(0,10,30\right.$ e $\left.60 \mathrm{~g} \mathrm{ha}^{-1}\right)$ e dois tamanhos de sementes classificadas em peneiras de crivo oblongo, num fatorial $4 \times 2$, com quatro repetições. Sementes maiores foram as retidas na peneira de malha de 16/64" x 19,05 mm (peneira $>16$ ) e sementes menores, aquelas que passaram na peneira de malha de 16/64" x $19,05 \mathrm{~mm}$ (peneira<16) e ficaram retidas na malha de 12/64" x 19,05 mm. As sementes, após serem colhidas, beneficiadas e secas "ao sol”, foram pesadas, tendo seu peso corrigido para $13 \%$ de umidade (base úmida) pela fórmula $\mathrm{PC}=\mathrm{P}_{\mathrm{ob}}(100-\mathrm{U}) / 100-13$, em que: $\mathrm{PC}=$ peso corrigido para $13 \%$ de umidade em base úmida e $\mathrm{P}_{\mathrm{ob}}=$ peso observado. Depois disso, procedeu-se ao armazenamento das sementes em câmara fria $\left(12^{\circ} \mathrm{C}\right.$ e $70 \%$ de umidade relativa) por 80 dias, sendo, após, realizadas as seguintes avaliações:

- Teste de germinação (TG): por meio da distribuição de 100 sementes em papel para germinação umedecido com água destilada na proporção de 2,5 vezes o peso do papel, que foram levados para germinador $\left(25^{\circ} \mathrm{C}\right)$, sendo a avaliação realizada aos cinco e nove dias após início do teste, segundo os critérios estabelecidos nas Regras para Análise de Sementes (Brasil, 1992). Os resultados foram expressos em porcentagem de plântulas normais.

- Primeira contagem da germinação: realizado, conjuntamente com o teste de germinação, avaliando-se o número de plântulas normais no quinto dia após a semeadura. Os resultados foram expressos em porcentagem de plântulas normais.
- Índice de velocidade de emergência (IVE): avaliado em casa de vegetação com 100 sementes de cada parcela, semeadas em bandejas plásticas, contendo substrato terra/ areia na proporção de 1:1. As bandejas foram irrigadas diariamente, sendo as contagens realizadas diariamente, a partir da emergência da primeira plântula. $\mathrm{O}$ cálculo do IVE foi feito segundo a metodologia proposta por Maguire (1962): $\mathrm{IVE}=\mathrm{E}_{1} / \mathrm{N}_{1}+\mathrm{E}_{2} / \mathrm{N}_{2}+\ldots$ $+\mathrm{E}_{\mathrm{n}} / \mathrm{N}_{\mathrm{n}}$, em que: IVE $=$ índice de velocidade de emergência; $\mathrm{E}_{1}, \mathrm{E}_{2}, \ldots \mathrm{E}_{\mathrm{n}}=$ número de plântulas emergidas no dia, computadas na primeira, segunda, ... última contagem; $\mathrm{N}_{1}$, $\mathrm{N}_{2}, \ldots \mathrm{N}_{\mathrm{n}}=$ número de dias da semeadura à primeira, segunda,... última contagem.

- Teste de sanidade das sementes (Blotter test) (Dhingra \& Sinclair, 1995): as sementes foram previamente desinfetadas em álcool a $50 \%$ por 30 segundos, em solução de $\mathrm{NaOCl}$ contendo 5\% de cloro ativo por $1 \mathrm{~min}$, seguindo duas lavagens em água destilada e esterilizada. Em seguida, as sementes foram incubadas em condições ótimas para o crescimento e esporulação do patógeno ou desenvolvimento dos sintomas nas sementes. Para isso, foram distribuídas 25 sementes em caixas plásticas gerbox com dimensões de 10,8 x 10,8 x $3,0 \mathrm{~cm}$ sobre três folhas de papel-filtro umedecidas com solução de $0,2 \%$ de 2,4 -D, a fim de retardar a germinação, em condições de assepsia. A umidade foi mantida durante o período de incubação com temperatura de $25{ }^{\circ} \mathrm{C}$ e fotoperíodo de 12 horas, durante sete dias. Após esse período, foram realizadas a identificação e a determinação da porcentagem de ocorrência dos fungos, utilizando-se microscópio estereoscópico e microscópio óptico. Os gêneros dos fungos foram identificados com base nas características morfológicas.

As mesmas avaliações foram realizadas por ocasião da colheita, sendo constatado que o carfentrazone-ethyl não promoveu efeito negativo sobre a germinação das sementes e emergência das plântulas.

Para todas as avaliações realizou-se análise de variância; a comparação das médias entre as peneiras, para cada dose, foi feita pelo teste $\mathrm{F}$ a $5 \%$ de probabilidade e, para as doses dentro de cada peneira, por regressão.

Planta Daninha, Viçosa-MG, v. 23, n. 4, p. 645-651, 2005 


\section{RESULTADOS E DISCUSSÃO}

Independentemente do tamanho das sementes, houve efeito das doses do herbicida sobre a porcentagem de plântulas normais tanto para o total de germinação como para a primeira contagem realizada aos cinco dias (Figura 1 e Tabela 1).

No teste de germinação, as sementes menores apresentaram valor acima de $80 \%$, inclusive nos tratamentos em que as plantas receberam a dose de $30 \mathrm{~g} \mathrm{ha}^{-1}$ do dessecante, sendo observada redução acentuada da germinação na maior dose testada do produto (60 $\left.\mathrm{g} \mathrm{ha}^{-1}\right)$, que foi inferior a 5\% (Figura 1). Para as sementes maiores, o efeito negativo do dessecante foi maior, com redução acentuada na germinação a partir da dose aplicada de $30 \mathrm{~g} \mathrm{ha}^{-1}$, o que inibiu mais de 50\% no desenvolvimento de plântulas normais (Figura 1).

$\mathrm{Na}$ primeira contagem, aos cinco dias, observou-se diminuição na porcentagem de plântulas normais em ambos os tamanhos de sementes com o aumento das doses do dessecante aplicadas nas plantas (Figura 1). Constatou-se, mesmo na ausência de aplicação do dessecante, diminuição média de 15\% na porcentagem de plântulas normais emergidas, fato atribuído exclusivamente ao armazenamento (Figura 1 e Tabela 1). Mesmo na menor dose aplicada (10 $\left.\mathrm{g} \mathrm{ha}^{-1}\right)$, a porcentagem de plântulas normais emergidas foi de $65,5 \%$ para as sementes menores e $56,5 \%$ para as maiores.

Quando se comparou a germinação das sementes entre os tamanhos, dentro de cada dose do dessecante, observou-se, na germinação, diferença para dose de $30 \mathrm{~g} \mathrm{ha}^{-1}$; nas sementes de tamanho maior a germinação foi menor, não ultrapassando $35 \%$, contra $89,5 \%$ nas sementes de menor tamanho, nessa mesma dose (Tabela 1). Isso pode se dever ao fato de que os tegumentos de sementes maiores são mais permeáveis, por serem menos espessos (Fuentes et al., 1984); dessa forma, tem-se maior área, passivel de absorver o produto, comprometendo assim a germinação
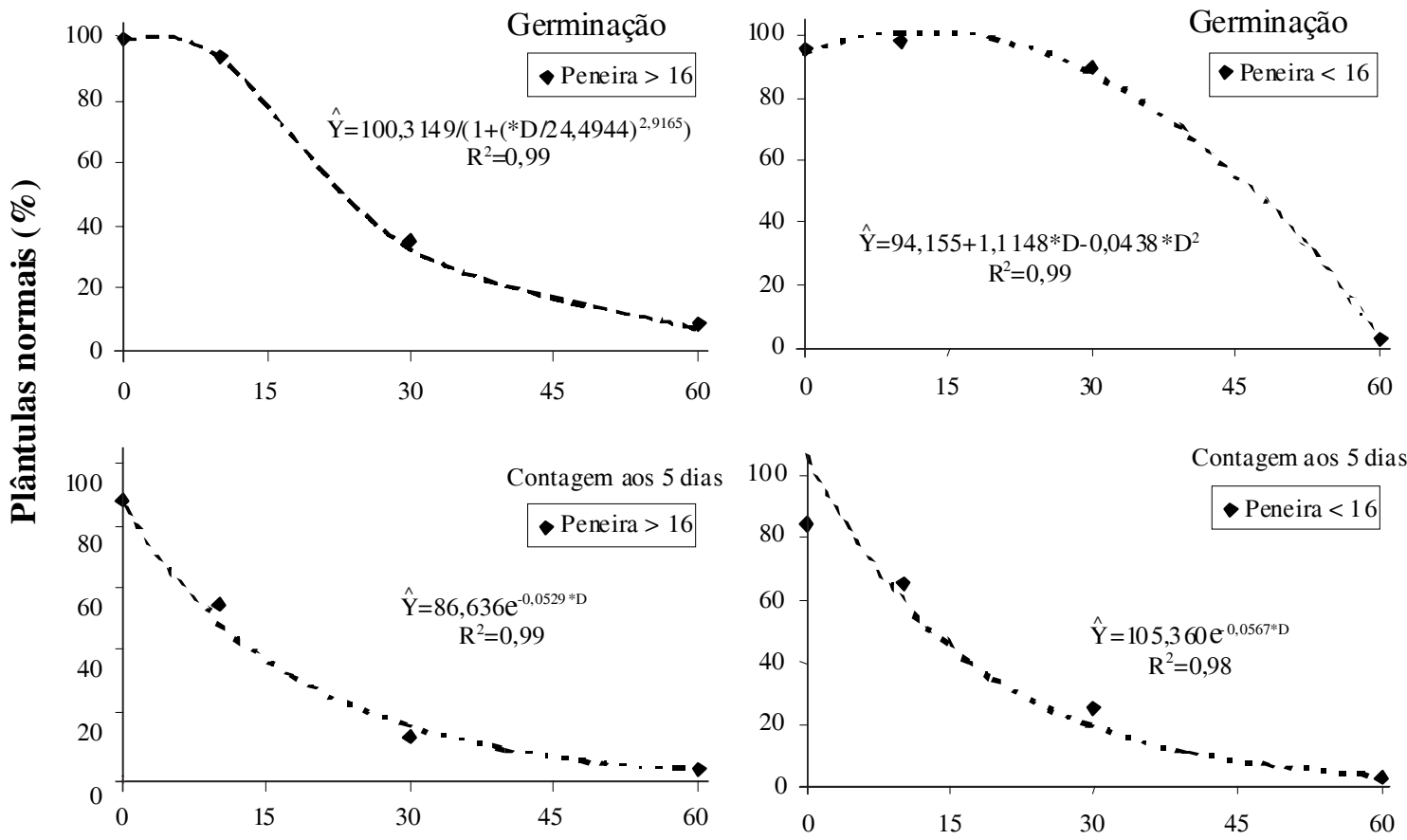

Doses do herbicida $\left(\mathrm{g} \mathrm{ha}^{-1}\right)$

Figura 1 - Efeito de doses de carfentrazone-ethyl sobre a porcentagem de germinação de sementes de feijão (cv. Talismã), classificadas em dois tamanhos, após armazenamento por 80 dias. 
Tabela 1 - Efeito de doses de carfentrazone-ethyl sobre a porcentagem de germinação de sementes de feijão (cv. Talismã), classificadas em dois tamanhos, após armazenamento por 80 dias

\begin{tabular}{|c|c|c|c|c|}
\hline \multirow{2}{*}{ Tamanho da semente } & \multicolumn{4}{|c|}{ Dose Aplicada $\left(\mathrm{g} \mathrm{ha}^{-1}\right)$} \\
\hline & 0,0 & 10,0 & 30,0 & 60,0 \\
\hline \multicolumn{5}{|c|}{ Germinação (\%) } \\
\hline Peneira $<16$ & $95,5 \mathrm{a}$ & $98,5 \mathrm{a}$ & $89,5 \mathrm{a}$ & $3,0 \mathrm{a}$ \\
\hline Peneira $>16$ & $99,5 \mathrm{a}$ & $94,5 \mathrm{a}$ & $35,0 \mathrm{~b}$ & $8,5 \mathrm{a}$ \\
\hline \multicolumn{5}{|l|}{$\mathrm{CV}(\%)$} \\
\hline \multicolumn{5}{|c|}{ Plântula normal (\%) - contagem aos 5 dias } \\
\hline Peneira $<16$ & $84,75 \mathrm{a}$ & $65,5 \mathrm{a}$ & $25,5 \mathrm{a}$ & $3,0 \mathrm{a}$ \\
\hline Peneira $>16$ & 89,50 a & $56,5 \mathrm{~b}$ & $14,0 \mathrm{~b}$ & $4,0 \mathrm{a}$ \\
\hline $\mathrm{CV}(\%)$ & \multicolumn{4}{|c|}{13,28} \\
\hline
\end{tabular}

* Médias seguidas por letras iguais na coluna, para cada dose e em cada contagem, não diferem entre si pelo teste de $\mathrm{F}$ a $5 \%$ de probabilidade de erro.

após certo tempo de armazenamento. Procópio et al. (2001), avaliando o efeito do herbicida smetolachlor sobre sementes de feijão (cultivar Pérola), observaram que plântulas originadas de sementes maiores foram mais suscetíveis ao herbicida quando comparadas àquelas oriundas de sementes menores. Fuentes et al. (1984) concluíram que os cultivares de feijão mais tolerantes ao alachlor apresentavam sementes escuras e de menor massa, sendo mais sensiveis aquelas de maior massa. Estes autores afirmam que as sementes de menor massa apresentam tegumento com maior espessura que as maiores, existindo, portanto, relação entre a massa das sementes e a quantidade de herbicida absorvido, ou seja, sementes leves promoveriam maior dificuldade à entrada do herbicida. Contudo, Cargil \& Santelmann (1971) observaram que o trifluralin causou maior nível de danos e redução da massa seca em raízes de plântulas de amendoim originadas de sementes menores, em relação às sementes "médias" e "maiores".

O índice de velocidade de emergência não foi diferente para as sementes em todos os tratamentos, sendo o valor médio observado de 11,57 dias. Resultados semelhantes para o IVE foram observados nos trabalhos conduzidos por Domingos et al. (1997) com outros dessecantes em sementes de feijão e por Marchiori Jr. et al. (2002) trabalhando com o carfentrazone-ethyl nas sementes de canola. Pode-se inferir que, apesar da anormalidade das plântulas nas sementes sob efeito do dessecante, evidenciada pelo TG, a emergência destas se dá na mesma velocidade que a das normais.

Pelo teste de sanidade (blotter test), foi possivel detectar vários fungos nas sementes dos diferentes tratamentos (Figura 2). Contudo, a porcentagem de fungos associados às sementes foi inferior a 7\% para todas as doses do dessecante aplicadas. Fungos do gênero Fusarium spp. geralmente desaparecem das sementes em poucos meses, pois não suportam a temperatura e a umidade de armazenamento (Soave \& Wetzel, 1987). Entretanto, fungos do gênero Penicillium spp. e Aspergillus spp. produzem toxinas que podem afetar as sementes, embora o estudo dos mecanismos de ação seja muito complexo (Soave \& Wetzel, 1987). A ocorrência desses fungos em sementes é comumente constatada na maioria das espécies cultivadas. A realização do teste de sanidade é de grande importância quando existe dúvida em relação à germinação das sementes. Neste estudo, a presença dos fungos não influenciou a germinação. A elevada anormalidade das plântulas se deu pela aplicação das maiores doses do herbicida por ocasião da dessecação. De forma semelhante, Marchiori Jr. et al. (2002) verificaram, para sementes de canola, presença de Alternaria spp. em tratamentos que receberam aplicação de carfentrazone-ethyl como dessecante em précolheita. Os autores atribuíram o fato à precipitação ocorrida em campo no dia seguinte à 


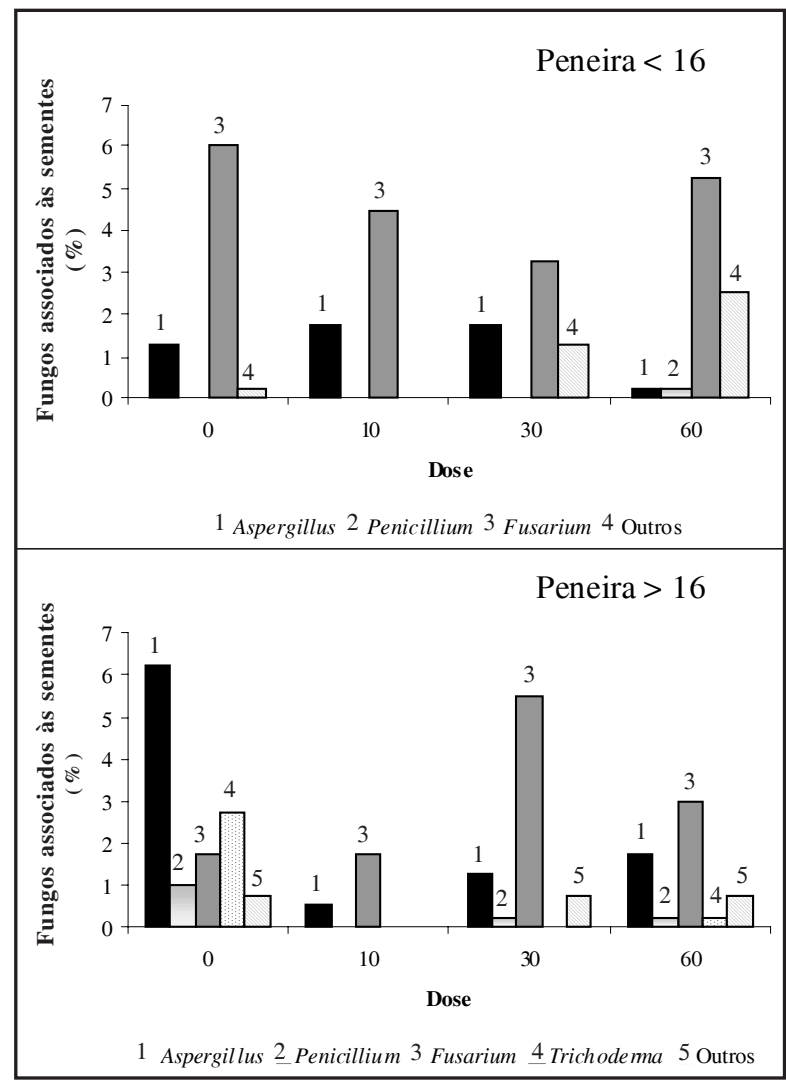

Figura 2 - Efeito de doses de carfentrazone-ethyl $\left(\mathrm{g} \mathrm{ha}^{-1}\right)$ sobre a porcentagem de fungos (spp.) associados às sementes de feijão (cv. Talismã), classificadas em dois tamanhos, após armazenamento por 80 dias.

aplicação do dessecante, o que favoreceu a entrada do patógeno. No presente estudo, a época de aplicação do dessecante foi considerada como fundamental para ótima atuação do produto, uma vez que aplicações realizadas longe da maturidade fisiológica ou em condições climáticas adversas, como em período chuvoso, poderiam comprometer a produtividade das sementes ou ainda mais a qualidade e o vigor destas.

Fazendo uma análise global dos dados, pode-se constatar que a utilização do carfentrazone-ethyl como dessecante, em précolheita de sementes de feijão, compromete o potencial fisiológico das sementes armazenadas, pois a presença de plântulas anormais originadas das sementes que receberam este dessecante pode reduzir o estande e, conseqüentemente, a produtividade de grãos da cultura.

\section{LITERATURA CITADA}

BRASIL. Ministério da Agricultura e Reforma Agrária. Regras para análise de sementes. Brasília: SNDA/DNDV/ CLAV, 1992. $365 \mathrm{p}$

CARGIL, R. L.; SANTELMANN, P. W. Influence of peanut seed and quality and variety on susceptibility to herbicides. Agron. J., v. 63, p. 98-100, 1971.

CORRÊA, L. E. A.; BORGES, A. Glyphosate + carfentrazone-ethyl: controle de ervas problemas. In: CONGRESSO BRASILEIRO DA CIÊNCIA DAS PLANTAS DANINHAS, 22., Foz do Iguaçu, 2000. Resumos... Iguaçu: SBCPD, 2000. p. 463.

CRUZ, J. L. et al. Relação entre rendimento, componentes primários de rendimento e parâmetros de enchimento de grãos de feijoeiro. R. Bras. Fisiol. Veg., v. 5, p. 159-162, 1993.

DHINGRA, O. D.; SINCLAIR, J. B. Basic plant pathology methods. 2.ed. London: Lewis Publishers, 1995. $442 \mathrm{p}$.

DOMINGOS, M.; SILVA, A. A.; SILVA, R. F. Qualidade de sementes de feijão afetada por dessecantes, em quatro estádios de aplicação. R. Bras. Sementes, v. 19, p. 276-283, 1997.

DOMINGOS, M.; SILVA, A. A.; SILVA, J. F. Qualidade da semente de feijão armazenada após dessecação química das plantas, em quatro estádios de aplicação. Acta Sci., v. 22, p. 1143-1148, 2000.

DURIGAN, J. C.; CARVALHO, N. M. Aplicação, em précolheita, de dessecantes em duas cultivares de soja (Glycine $\max ($ L.) Merril. I - Efeitos imediatos sobre a germinação e produção de sementes. Planta Daninha, v. 3, n. 1, p. $108-115,1980$.

FUENTES, J. R. et al. Tolerância de cultivares de feijão (Phaseolus vulgaris L.) aos herbicidas alachlor e linuron. R. Ceres, v. 31, p. 136-145, 1984.

GUIMARÃES, S. C.; SOUZA, I. F.; PINHO, E. V. R. V. Viabilidade de sementes de erva-de-touro, sob diferentes condições de armazenamento. Planta Daninha, v. 22, n. 2, p. $231-238,2004$.

HERBICIDE-RESISTENCE-ACTION-COMMITEE HRAC. Classification of herbicides according to mode of action. Disponível em: <http://www.plantprotection.org/ hrac/moa2001.htm>. Acesso em: 29 jan. 2001.

INOUE, M. H. et al. Rendimento de grãos e qualidade de sementes de soja após a aplicação de herbicidas dessecantes. Ci. Rural, v. 33, n. 4, p. 769-770, 2003.

LACERDA, A. L. S. et al. Aplicação de dessecantes na cultura da soja: antecipação da colheita e produção de sementes. Planta Daninha, v. 19, n. 3, p. 381-390, 2001.

LACERDA, A. L. S. et al. Aplicação de dessecantes na cultura da soja: teor de umidade nas sementes e biomassa nas plantas. Planta Daninha, v. 21, n. 3, p. 427-434, 2003. 
MAGAlHÃES, P. C.; DURÃES, F. O. M.; KARAM, D. Eficiência dos dessecantes paraquat e diquat na antecipação da colheita do milho. Planta Daninha, v. 20, n. 3, p. 449-455, 2002.

MAGUIRE, J. D. Speed of germination - aid in selection and evaluation for seedlings emergence and vigor. Crop Sci., v. 2, n. 1, p. 176-177, 1962.

MARCHIORI JR., O. et al. Qualidade e produtividade de sementes de canola (Brassica napus) após aplicação de dessecantes em pré-colheita. Planta Daninha, v. 20, n. 2, p. $253-262,2002$.

OSIPE, R. et al. Eficácia e seletividade dos herbicidas: Shark e Aurora, aplicados isoladamente e em mistura com Roundup, em pós-emergência, jato dirigido na cultura do café. In: CONGRESSO BRASILEIRO DA CIÊNCIA DAS PLANTAS DANINHAS, 22., 2000, Foz do Iguaçu-PR. Resumos... Londrina: SBCPD, 2000. p. 446.
PORTELA, C. M. O.; COBUCCI, T. Praticabilidade agronômica da dessecação em pré-colheita do feijoeiro. In: REUNIÃO NACIONAL DE PESQUISA DE FEIJÃO, 6., 1999, Goiânia. Anais... Goiânia: EMBRAPA/EBDA, 1999. p. $507-510$.

PROCÓPIO, S. O. et al. Efeito do tamanho de sementes sobre a tolerância do feijoeiro ao s-metolachlor, em condições de baixa temperatura. R. Bras. Herb., v. 2, n. 3, p. 133-142, 2001.

SANTOS, J. B. et al. Qualidade de sementes de feijão (Phaseolus vulgaris) após aplicação do carfentrazone-ethyl em pré-colheita. Planta Daninha, v. 22, n. 4, p. 633-639, 2004.

SOAVE, J. R.; WETZEL, M. V. S. Patologia de sementes. Campinas: Fundação Cargil, 1987. 480 p. 